\title{
TRAJETÓRIA ESCOLAR DO SURDO NO ENSINO SUPERIOR: CONDIÇÕES E POSSIBILIDADES ${ }^{1}$
}

SCHOOL PERFORM ANCE OF THE DEAF IN HIGHER EDU CATION: CONDITIONS AND POSSIBILITIES

José Ildon Gonçalves da CRUZ²

Tárcia Regina da Silveira DIAS 3

RESUM O: devido ao número relativamente pequeno de surdos que frequentam o ensino superior, este estudo objetivou conhecer as suas condições nesse nível de ensino. Participaram da pesquisa sete surdos universitários, na faixa etária entre 22 e 39 anos. Os dados foram obtidos por meio de entrevistas individuais sucessivas, presenciais ou à distância, via internet, empregando o português falado, escrito ou a língua de sinais, com a mediação de intérprete. Realizaram-se dez entrevistas presenciais, gravadas e transcritas, e onze à distância, mediante e-mail e $\mathrm{M}$ essenger ${ }^{\circledR}$. Os relatos foram analisados sob o ponto de vista sócioantropológico, que entende os surdos como diferentes, linguística e culturalmente, pertencentes aos grupos minoritários e que frequentam, na maioria das vezes, uma escola organizada para ouvintes e padronizada. Os resultados apontam que as condições dos surdos no ensino superior são de dificuldades, de impedimentos, de abandono e de rejeição. Os surdos são obrigados a se responsabilizarem por sua aprendizagem, priorizando o trabal ho extra classe para recuperação de notas. A escola se organiza de acordo com interesses e necessidades dos ouvintes, isto é: não há uma língua compartilhada com os alunos surdos, não há intérprete português-Libras, não há contexto bicultural, não há interlocução na escola. Concluiu-se que os surdos são capazes, produtivos, solidários e interessados em avançar no seu processo de escolarização, apesar dos empecilhos encontrados no interior do espaço escolar.

PALAVRAS-CHAVE: surdez; ensino superior; comunidade linguística; educação especial.

ABSTRACT: Due to the relatively small number of deaf students enrolled in higher education, this study aimed to look at learning conditions at that educational level. Seven deaf college students, aged 22-39, participated in the research study. Data was collected through successive individual interviews, in person or by internet, using Portuguese language in spoken or written form or through the manual alphabet with the help of an interpreter. Ten in-person interviews were conducted, which were recorded and transcribed, and eleven were doneusing e-mail and $M$ essenger ${ }^{\circledR}$. The reports wereanalyzed under the socio-anthropological reference that understands the deaf as people who are linguistically and culturally different, belonging to minority groups and who, usually, attend standard hearing-oriented schools. The results show that deaf college students face difficulties, impairments, abandonment and rejection in higher education. They are required to take on the responsibility for their own learning, which includes after-class sessions to compensate for low grades. The school is organized according to the interests and needs of hearing students, i.e. there is no shared language for deaf students; there is no Portuguese-LIBRAS (Brazilian Signal Language) interpreter; there is no bicultural context; there is no dial ogue at school. In conclusion, deaf peopleare capable, productive, characterized by solidarity and interested in advancing in their educational processes, despite the barriers they face daily in the university environment.

KEYWORDS: deafness; higher education; linguistic community; special education.

1 Este artigo é uma versão resumida da dissertação: Consolidação de uma trajetória escolar: o olhar do surdo universitário sobre o ensino superior (CRUZ, 2007), realizada no Programa de Pós-Graduação em Educação Escolar do Centro Universitário Moura Lacerda, Ribeirão Preto, SP.

2 Mestre em Educação Escolar. Professor da Rede Pública de Ensino do Estado de São Paulo. Membro Efetivo da Academia Barretense de Cultura. joseildo@hotmail.com

3 Doutora em Psicologia pela Universidade de São Paulo-SP, Mestre em Psicologia pela Universidade Nacional Autônoma do M éxico-M éxico e Professora-Orientadora do Programa de Pós-Graduação em Educação Escolar do Centro Universitário Moura Lacerda - Ribeirão Preto. tdias@netsite.com.br 
O presente estudo entendea surdez como experiências einter-relações visuais e os surdos como diferentes linguisticamente, bilíngues, biculturais, pertencentes a uma comunidade linguística que os apresenta como pessoas que se comunicam, interagem e se posicionam na "experiência visual" (SKLIAR, 1999, p. 11; FRAN CO, 1998, p. 74). São reconhecidos "em relação à experiência visual e longe da experiência auditiva” (PERLIN, 1998, p. 54). Graças à dimensão dessa experiência visual devem ser compreendidos como sujeitos culturais e, por isso, diferentes da "condição de deficiente" (IPUF, 2005, p. 2). Para Lunardi e Skliar (2000), os surdos apresentam "uma diferença política e uma experiência visual" (p. 20), que valorizam o "olhar no lugar do ouvir" (LULKIN, 1998, p. 47), porque "não são pessoas que não ouvem, são pessoas que vêem" (SÁ, 1998, p. 176), cuja língua “traduz a experiência visual" (QUADROS, 2004, p. 55). Para o surdo, o acesso ao conhecimento está "intimamente ligado ao uso comum de um código linguístico prioritariamente visual, uma vez que, de outra forma, [...] poderá apenas ter acesso às características físicas do objeto e não as conceituais" (BRASIL, 2005b, p. 83). Segundo Gesueli (2006), a identidade do surdo "se constrói dentro de uma cultura visual" (p. 284), porque a sua língua é vista no corpo do outro. A esse respeito, Quadros (2006) explica que "os surdos vêem a língua que o outro produz por meio do olhar, das mãos, das expressões faciais e do corpo. É uma língua vista no outro" (p. 2).

A atual legislação também destaca que o surdo "compreende e interage com o mundo por meio de experiências visuais, manifestando sua cultura principalmente pelo uso da Língua Brasileira de Sinais - Libras" (BRASI L, 2005a, art 20).

Esta comunidade tem a sua língua, que no Brasil é denominada de Libras (BRA SI L, 2002). Uma língua viva (DIAS et al . 2001, p. 4), densa, "completa [...] a qual não oferece nenhuma dificuldade para ser adquirida" (PEREIRA, 2004, p. 45) com seus códigos, gramática, léxicos e símbolos que se renovam, e que é

[...] composta de movimentos e formatos específicos de mãos, braços, olhos, face, cabeça e postura corporal, que combinados fornecem as características gramaticais necessárias para a formação de uma língua [...]. É a única língua que permite à pessoa surda aceder a todas as características linguísticas (LIMA et al., 2003, p. 46).

O surdo pertencea uma comunidade de mi norialinguística e, também, cultural, "baseando-se no fato de que a língua de sinais é utilizada por um grupo restrito de usuários" (SKLIAR, 1998, p. 22) que carrega em si uma cultura própria e específica, compreendida como uma diferença na multiplicidade humana. O surdo, de acordo com Sá (1998), traz a identificação do grupo, da comunidade a qual pertence e argumenta com base em sua legitimidade enquanto membro de sua comunidade pela qual fala sem constrangimento (p. 179). 
A comunidade surda, portanto, é "caracterizada por compartilhar uma Língua deSinais eval ores culturais, hábitos emodos de socialização próprios" (SKLIAR,1997, p. 143), e é, também, compreendida como pertencente aos grupos minoritários (KAUCHAKJE, 2003, p. 67) como os afro-descendentes os índios, as profissionais do sexo, os homossexuais, as mulheres, os idosos... Pessoas que têm sido "definidas, desvalorizadas e discriminadas por representarem 'o outro', 'o diferente', 'o inferior' " (MOREIRA, 2002, p. 18). A comunidade surda pode ser comparada a outras comunidades vistas como subalternas, como "os indígenas, os negros, as mulheres, os loucos" (SKLIAR,1998, p. 16).

Esses grupos minoritários não devem ser entendidos em relação à quantidade de pessoas a ele pertencente, mas como grupos que, ao longo do tempo, foram sendo colocados à parte do processo político-social e da vivência da cidadania.

O termo "minoria" nunca se refere a uma medida numérica de um grupo. Às vezes, inclusive, alguns grupos representam quantitativamente uma mai oria numa população determinada - os negros na África do Sul, por exemplo. Não é então o quantitativo o que demarca o território minoritário e majoritário, esim, um certo tipo de mecanismo de poder, aquel e que outorga tal condição: um mecanismo de poder que a nossa tradição tentou traduzir em termos de uma relação entre dominantes e subordinados (SKLIAR, 2003, p. 9).

Estes grupos estão em estado de “não poder" econômico, educacional, político, jurídico e social.

Nessa condição de "não poder", os surdos foram compreendidos e chamados por "deficientes auditivos" (MOURA, 2000, p. 51), "pessoas com deficiências" (FERREIRA; GUIMARÃES, 2003, p. 32), pessoas "portadoras de necessidades especiais" (BRASIL, 1996, art 58), "portadores de deficiência" (BRASIL, 2005a, inciso III; FLEURI, 2003, p. 9) ou "portador de deficiência auditiva [...] deficientes, como incapazes" (DORZIAT, 2004, p. 80; CONADE, 2006, p. 1).

O vocábulo deficiente traz em sua raiz latina o significado de “fadiga, esgotamento, defecção, defeito, incompletude, desertor, traidor, diminuído, abandono, revolta, abalar, desanimar, perder as forças, transgredir" (DICIONÁRIO LATIM PORTUGUÊS, 2000) e em sua raiz grega, deficiente é "falta, imperfeição numa obra, insuficiência" (PEREIRA, 1990). Necessidade, etimologicamente, é “obrigação, situação embaraçosa, indigência” (DICIONÁ RIO LATIM PORTUGUÊS, 2000). O “vocábulo ‘necessidades' tem várias significações o que o torna polissêmico, incluindo as ideias de carência, de precisar de algo, do que é inevitável, imprescindível e de exigências mínimas: generalizadas ou específicas" (CARVALHO, 2004, p. 169). São vocábulos históricos que envolvem conceitos clínicos, "medicalização, correção, caridade e beneficência" (SKLIAR, 2003, p. 167) e que pressupõem uma busca de ajuda e de cura. 
Compreender o surdo nessa perspectiva é permanecer no ponto de vista "clínico-terapêutico" (SKLIAR, 1997, p. 10) "que relaciona surdez com patologia e déficit biológico [...], a processo de reabilitação e correção da fala" (PEDROSO, 2001, p. 15) e que tem como finalidade, além de recuperar a expressão oral, tentar, de todas as formas e com todos os meios, que a pessoa surda adquira a possibilidade de ouvir e falar e de se tornar uma pessoa ouvinte. $\mathrm{Na}$ "vida dos surdos o ser sempre foi relacionado ao ouvir, ao falar e, em consequência, a tudo que estas habilidades representavam" (DORZIAT, 2004, p. 83).

O ponto de vista clínico-terapêutico é a negação da surdez como constituição do ser e da diferença surda e um empecilho para a compreensão da mesma. Significa afirmar que os surdos não são pessoas completas porque não ouvem e que possuem uma perda que carece ser sanada. Esta política significa um "conjunto de representações dos ouvintes a partir do qual o surdo está obrigado a olhar-se e a narrar-se como se fosse ouvinte" (SKLIAR, 1998, p. 15), e, ainda, conforme Dorziat (2004), "transplante linear dos modos de elaboração e produção dos conhecimentos dos ouvintes para os surdos" (p. 81).

Essa visão de surdos dentro da sociedade tem sido reproduzida na escola, queseconstitui, em sua grandemaioria, como monolíngueemonocultural, organizada e planejada para os ouvintes, e que tem ignorado a surdez e o que se refere aos surdos e às suas diferenças.

Considerando essa condição do surdo na sociedade e na escola, a presente pesquisa tem como núcleo descrever e analisar as atuais condições dos alunos surdos na escola, especificamente no ensino superior, sob o ponto de vista desses al unos esob a perspectiva sócio-antropológica da surdez. Buscou descrever e analisar as condições de ingresso, de permanência e de conclusão de curso de alunos surdos no ensino superior, tendo por base as experiências por el es relatadas.

Este tipo de estudo se justifica porque os dados sobre a presença de pessoas surdas e de suas condições nas instituições de ensino superior são incipientes.

Além disso, o interesse em estudar tal assunto também veio de um impasse vivido por um dos pesquisadores, que sendo docente em uma faculdade de pedagogia, se deparou com um aluno surdo em sala de aula. Só conseguiu perceber estealuno como surdo após um semestre de aulas. Foi complicado, difícil. Eram dois estrangeiros tentando se comunicar, cada um a seu jeito, tratando de assuntos puramente teóricos de introdução à filosofia. Não somente desconhecia a realidade do aluno, como descobria que ela era incompreensível para si.

Era necessário mudar para apoiar o aluno, para oferecer-lhe o que precisava para a sua aprendizagem e para o seu desenvolvimento educacional e humano. Tornara-se imperativo trazer o discurso e as exigências do aluno surdo para a sala de aula. 
Foi preciso reconhecer a existência deste aluno, descobrir que não o compreendia, buscar se descentralizar de suas certezas e escolher se dedicar, estudar e pesquisar o lócus reservado aos surdos que conseguem chegar ao ensino superior, as suas atuais condições nesta modalidade de ensino a partir do que têm a dizer sobre elas.

Essa experiência do pesquisador possibilitou ir além, despertar “o desejo de outro lugar e de outra coisa que, nesse caso, poderia ser identificado como novas possibilidades de relações pessoais e sociais entre sujeitos marcados por uma política de diferenças" (SOUZA; FLEURI, 2003, p. 62).

Participaram do estudo sete surdos, sendo cinco que terminaram a graduação, um que ainda a estava cursando e um que desistira dos três cursos superiores que iniciara. Esses participantes foram denominados S1, S2 e assim por diante. O primeiro participante (S1) tem 25 anos, é divorciado e surdo profundo, nos dois ouvidos. Estudou em classe especial da Escola DERDIC, que foi muito importante para el e e o ajudou muito. Foi nessa escola que aprendeu libras e começou a falar nas aulas de fonoaudiologia. Terminou o curso de pedagogia em 2005. A segunda participante (S2) tem 37 anos, é divorciada, tem uma filha, é avó e aposentada por invalidez causada por lesão por esforço repetitivo. Ficou surda aos doze anos em consequência de meningite. Fez tratamento, mas teve sequelas na fala. A surdez veio gradualmente. Não sabe qual o seu grau de perda auditiva. Comunica-se com os ouvintes via leitura labial, mas enfrenta muitas dificuldades. Terminou o curso de Pedagogia em 2003. A terceira participante (S3) tem 33 anos, é separada, sem filhos, nasceu surda. Tem perda severa no ouvido direito e profunda no ouvido esquerdo. Ouviu com aparelho, mas hoje perdeu totalmente a audição porque a medicação no tratamento de uma gripe a afetou. No começo aprendeu a fazer a leitura labial, mas foi muito difícil. Está no último período do curso de Pedagogia. A quarta participante (S4) tem 26 anos, é solteira, surda desde o nascimento porque sua mãe teve rubéola. Escuta com aparelho. Estudou Fisioterapia por seis meses em 2000; Ciência da Computação por dois meses em 2001 e Gestão em Instituições Financeiras por quatro meses em 2004 e três meses em 2005. Não terminou nenhum destes cursos. A quinta participante (S5) tem 24 anos, solteira, sem filhos, nasceu surda devido à rubéola congênita. Tem perda profunda nos dois ouvidos. Concluiu Ciência da Computação em 2004. A sexta participante (S6) tem 24 anos, solteira, sem filhos, nasceu ouvinte, mas aos três anos de idade, em consequência de meningite, aos poucos foi perdendo a audição. Hoje, escuta com ajuda de aparelho. Tem $30 \%$ de perda auditiva no ouvido esquerdo e perda severa no ouvido direito. Faz uso da leitura labial. Concluiu a Graduação em Ciências da Computação no ano de 2004. O sétimo participante (S7) tem 22 anos, solteiro, sem filhos, nasceu surdo, mas escuta um pouco com o uso de aparelho e aprendeu sinais com os amigos surdos e utiliza a leitura labial. Tem $90 \%$ de perda auditiva, mas não sabe em qual ouvido ou se nos dois. Desconhece os motivos pelos quais ficou surdo. Concluiu Processamento de Dados em 2006. 
Os dados foram obtidos por meio deentrevistas individuais sucessivas, presenciais ou via internet, empregando o português falado, escrito ou a língua de sinais com o apoio de intérprete. $N$ as entrevistas presenciais foram utilizados gravador portátil e fita cassete para gravá-las e na via internet, foram armazenadas em forma de arquivo de textos.

Realizaram-se dez entrevistas presenciais gravadas etranscritas. A pós cada transcrição, essas entrevistas eram analisadas, servindo de base à próxima sessão. Realizaram-se onze entrevistas via internet que foram gravadas em arquivos do M icrosoft Word.

Nas entrevistas individuais, foram utilizados gravador, microfonesem fio efita cassete. Nas entrevistas, via internet, foram utilizados o e-mail eM essenger, programa de mensagens instantâneas criado pela M icrosoft Corporation.

Com $\mathrm{S} 1$ eS2, foram realizadas entrevistas presencias e gravadas. Com S3, houve a presença de intérprete. Com S4, S5, S6 e S7, as entrevistas foram realizadas via email e $M$ essenger.

As entrevistas foram lidas e relidas para identificar temas e subtemas que permitissem descrever e analisar as condições do surdo adulto no ensino superior.

Pelos relatos dos universitários surdos o processo de escolarização é entremeado de dificuldades. Todos os participantes relatam transtornos e sofrimentos, como por exemplo, serem obrigados a aprender a falar, a avisar aos professores queeram surdos, a não usar sinais, a escrever perfeitamenteem Língua Portuguesa.

Segundo os depoimentos, os surdos que ingressaram no ensino

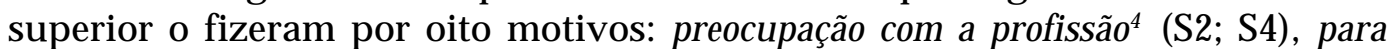
subir de cargo (S2), melhorar o salário (S2), satisfazer a curiosidade de como era 0 curso superior (S4), melhorar a vida (S3), montar uma escola (S2), ajudar os surdos no processo educacional (S1; S3; S5) ou ser professor surdo (S1).

A escol ha da maioria dos participantes foi o curso depedagogia, porque, segundo depõe, trata da educação e ensina como trabalhar com aluno (S1; S2; S3). Percebe-se, pelos relatos, que a escolha destes participantes tem um propósito determinado, ou seja, trabalhar no ensino-aprendizagem do aluno surdo.

Decidiram pelo curso porque perceberam que a pedagogia trabalha com a educação e, para eles, a mai oria das dificuldades dos surdos está relacionada aos processos educacionais. Muitas dessas dificuldades do aluno surdo vêm sendo discutidas por alguns pesquisadores, como Favorito (2006) e Pedroso (2001).

${ }^{4}$ As expressões utilizadas pelos participantes, ou paráfrases de suas falas, serão, doravante, transcritas em itálico. 
Quem ingressou no ensino superior sem essa perspectiva, depois de concluído o curso, percebeu que poderia ter escol hido um curso mais adequado para ajudar aos demais surdos em seu processo educacional. Perceberam, também, que, primeiramente, se deve investir no processo educacional dos surdos.

Neste estudo, os surdos distinguem duas modalidades de curso superior, exatas e humanas. A área de humanas parece mais apropriada para oferecer ajuda aos outros surdos em seu processo educacional. Os surdos que escolheram a área de exatas perceberam que se tivessem escolhido o curso de pedagogia poderiam ter tido mais oportunidades de ajudar a comunidade surda, porque a pedagogia trata diretamente da educação. Essa modalidade permite ao surdo se tornar, especificamente, um educador surdo. Para apenas ter uma profissão, a área de exatas é suficiente, como por exemplo, ciências contábeis, processamento de dados, ciência da computação e análise de sistemas. Um surdo (S5) que fez ciência da computação diz que hoje faria pedagogia para poder ajudar os surdos. Não se arrependeu por ter feito este curso, mas hoje, com a consciência que tem sobre o processo educacional do surdo, não perderia tempo e ingressaria no curso de pedagogia.

No ensino superior, as modalidades de comunicação utilizadas com os surdos são, basicamente, o oralismo e a comunicação total. No oralismo, o surdo é obrigado a utilizar a língua oral dos ouvintes na comunicação. Mas, o surdo não compreende a voz humana pela audição (TARTUCI, 2005), logo, ele se vale da leitura labial para tentar entender o que os ouvintes estão compartilhando, oralmente, em sala de aula. Para um surdo, participante da pesquisa, a leitura labial, além de provocar dor de cabeça e dores nos olhos, é "a mesma coisa que nada" e outro relatou que é muito cansativa.

$\mathrm{Na}$ modalidade comunicação total são agregados elementos como leitura labial, gestos, mímicas ou quaisquer outros meios para que o aluno surdo e os ouvintes possam, ainda com base em elementos concretos, se entender em sala de aula.

Estas duas modalidades não proporcionam uma comunicação que dê conta da reflexão e do pensamento abstrato e acabam dificultando o avanço do processo humano e educacional do surdo por não serem uma língua, como é a libras. Um participante (S3) assim declara: Penso no futuro, na educação dos surdos, porque sempre convivi com professores oralistas e nunca vi que tivesse um professor surdo, que se preocupasse com o surdo. Eu me preocupo com o desenvolvimento do surdo, quero ajudar o surdo no futuro.

Como o processo de escolarização do surdo é entremeado de dificuldades, o surdo queavançou um pouco mais na escolaridadetem consciência queos demais surdos devem ser ajudados para conseguirem ultrapassar os mesmos obstáculos e impedimentos. Ele se sente impelido a ajudá-los porque conhece as dificuldades dos surdos em sala de aula. 
A primeira alternativa relatada para concretizar esse objetivo é o trabalho voluntário. Ajudar aos demais surdos, independente de qualquer benefício próprio. Auxiliar docentes e surdos a entenderem as dificuldades dos surdos e a superarem dúvidas. Contudo, há muitos empecilhos aos surdos que trabalham voluntariamente na escola. O empecilho mais dramático e mais significativo veio de uma diretoria de ensino que não permitiu a presença do surdo em uma escola de sua rede, depois de oito meses exercendo trabal ho voluntário, porque este não dispunha de diploma de ensino superior. Como o surdo pode trabalhar na escola se a maioria deles não cursou o ensino superior? Nem o trabalho voluntário é possível sem o diploma de conclusão de curso superior. A ausência dos surdos na escola dificulta a reorganização da mesma para propor um ensino de qualidade a esses alunos.

Outras dificuldades relatadas pelos surdos no ensino superior se referem à comunicação. A escola, sendo organizada e planejada para ouvintes e por ouvintes, não tem uma língua compartilhada com os surdos. Com a ausência de uma língua comum torna-se quase impossível a interlocução surdos-ouvintes e as demais dificul dades fluem em decorrência.

Geralmente, o surdo se vê obrigado a se apresentar a cada professor, dizendo-Ihe que é surdo e que há necessidade de uma postura mais flexível por parte do mesmo. Às vezes, os colegas falam que há surdo na sala.

A disposição dos móveis na sala de aula, a organização das carteiras e cadei ras em filas, impede o surdo de visualizar a face do professor e dos demais alunos, ou seja, de compreender o que está acontecendo. Esta dificuldade é uma das que fazem o surdo acreditar que no ensino superior tudo é lançado para ele, que deve aprender por conta própria. Ele quem deve criar contextos educacionais para a sua aprendizagem.

Entre outras dificuldades, estão as perguntas sobre vocabulário que o surdo é obrigado a fazer para entender as frases. Isto incomoda o professor, o deixa irritado. Os relatos mostram que o surdo percebe esta irritação como falta de paciência do professor.

As aulas expositivas, os surdos as chamam de aulas falantes, aulas não escritas, com microfone. Essas aulas são percebidas como mais rápidas, por esconderem os lábios do professor enão permitirem a leitura labial. Essas condições são relatadas como piores, se o professor usa barba e bigode, mesmo, se nesse caso, fale devagar e de frente para o surdo. Como no depoimento de (S2): $\mathrm{Na}$ faculdade eu tive bastante dificuldade de interpretação de texto, de leitura, slide. Ler slide para mim era muito rápido, passar slide. Tinha várias pessoas que trabal havam em cima de slide, passava muito rápido e não dava nem para prestar atenção na professora nem no telão. O surdo necessita de tempo para visualizar a informação, para se contextualizar, porque não está acompanhando a explicação oral do professor, como acontece com o ouvinte. Como dito, ele "compreende e interage com o mundo por meio de experiências visuais" (BRASIL, 2005a). 
Quando se utiliza vídeo em sala, os depoimentos revelam que as dificuldades aumentam porque a legenda rápida em português e a visualização da imagem tornam impossível a compreensão.

Nas aulas expositivas, no cotidiano da escola, o professor fala rápido, de costas para os alunos, ignorando a presença do surdo em sala, tal como (S3) declara:

Percebo que as pessoas não conseguem compreender, se comunicar. P or exemplo, na faculdade, sinto esta dificuldade porque os amigos, quan do estão fazen do as atividades, esquecem que sou surda: falam nas minhas costas. 0 professor fala na frente, não dá aten ção pra mim, vai andando e sempre esquece que tem um surdo do lado. A s pessoas continuam falando, falando, e eu não entendo nada.

Há disciplinas que são mais fáceis para o surdo, como as de didática e cálculo. As que apresentam mais dificuldades são filosofia e sociologia, isto é, as de conteúdo mais abstrato e vocabulário específico. Para o surdo ter acesso a esses conteúdos é necessário uma língua compartilhada. Como aparece no depoimento de um entrevistado, que cursou pedagogia, sobre a disciplina matemática e interpretação, que é própria da disci plina língua portuguesa: porque eu lendo para mim não dava nada certo, não entrava nada [...], não entrava nada na interpretação, principalmente na área da matemática. Eu tinha que conversar com os números, eu tinha que conversar bastante, falar alto com os números para poder gravar mesmo no cér ebro (S2).

cérebro.

Ou, em outras palavras, o surdo tinha que decorar para gravar no

Outra dificuldade mencionada foi compreender as matérias, raciocinar e interpretar conteúdos. Como é o caso de um dos participantes: ele copiava tudo que era escrito na lousa e depois, em casa, um familiar ou um colega lia várias vezes o que copiara. Esse participante também explica que na sua classe estudava uma aluna com visão subnormal. O aluno surdo copiava e, no dia seguinte, a colega com perda visual, com uma lupa, lia e lhe explicava a matéria. Deste modo, compreendia com mais facilidade, como diz: Tive uma col ega que era cega, e eu como não captava rápido o entendimento, eu copiava a matéria para ela e ela transmitia o rascunho da aula pra mim, eu pegava e compreen dia. Ela lia e eu compreendia mais fácil (S2). Somente por meio desta estratégia acessava o conteúdo dado em sala de aula.

A interação professor ouvinte-aluno surdo se caracterizava, conforme relatos, pela falta de percepção do aluno surdo por parte do professor e pelo sentimento de revolta por parte de al uno surdo. O professor não sabia como agir com esse aluno e acabava ignorando-o, agindo com agressividade ou pedindo para que tivesse paciência: você é a primeira surda aqui na faculdade, eu não estou acostumada, tenha paciência (S3). 
Um episódio de agressividade foi assim expresso: um dia, eu tornei a perguntar, me levantei, e perguntei de novo. Eu lembro que ele veio e bateu a mão na mesa, pra [...] ficar quieta (S2).

O aluno surdo no ensino superior pode se mostrar insistente porque quer aprender e essa insistência parece dificultar a implementação do assunto planejado para a aula.

Nesta inter-relação, o surdo diz preferir as mulheres como professoras por serem mais sensíveis do que os homens: São atenciosas, conversam, tentam escutar. Por exemplo, um participante relata: Era difícil ter diálogo com professor homem. Com mulher é mais fácil, porque a mulher é mais sensível, dá mais atenção. A mulher é diferente. É muito diferente mesmo (S2).

O professor, homem, em sala de aula, émuito objetivo: começa etermina a aula sem uma preocupação com 0 aluno surdo e sem demonstrar paciência e atenção com 0 surdo. Um dos participantes diz: 0 homem não tem muita paciência, fica nervoso. Eu prefiro mulher (S3). Para os participantes, o professor reage de forma agressiva às interpelações do surdo e o surdo interpreta esta reação como preconceito do professor: preconceito de você perguntar, o professor vinha e falava é mentira, você não sabe de nada, é melhor você estudar mais (S2).

Esta fala revela o descrédito que o professor pode apresentar pelo aluno surdo. O aluno é mentiroso e nada sabe. Parece, também, que a expressão “é melhor você estudar mais" é um eufemismo para incapaz, improdutivo e anormal.

Para avaliar o aluno surdo, os professores dão trabalhos extraclasses porque, nas provas organizadas para ouvintes, os surdos, geralmente, não atingem o conceito considerado suficiente. Visando recuperar a nota desse aluno, os professores prescrevem trabalhos fora da sala de aula. Estes trabalhos, de fato, não ajudam a aprender, parecem mais uma maneira de documentar a nota na disciplina. Nesse caso, a preocupação parece ser apenas com a nota.

O sistema de avaliação do surdo, no ensino superior, nas condições educacionais organizadas para os ouvintes, parece levar a exclusão desse aluno do processo de aprendizagem. Exemplos dessas avaliações são as provas em língua portuguesa, a ausência de intérprete nessas condições, a descontextualização das questões de prova e o vocabulário inadequado para a compreensão do surdo, conforme mencionam os entrevistados.

Nesse contexto, o surdo percebe que tem que aprender por conta própria, de seu jeito. Um entrevistado relata que, depois de perguntar várias vezes e o professor reagir com violência, descobriu que tinha de aprender uma forma de saber o que o professor fal ava e, sem alternativa, buscou a aprender leitura labial: depois daquele dia que eu entendi que eu tinha que aprender rápido o labial para poder ter mais, assim, entendimento, por causa do medo, por causa do medo a gente tem que aprender rápido (S2). 
Esse depoimento revela como condições educacionais inapropriadas para o ensino desurdos geram o medo das reações do professor: se não aprendesse leitura labial, a violência do professor continuaria, sem que nada se modificasse na escola.

Em dias de prova, o comportamento do surdo era de nervosismo e inquietação: na época de prova, eles pegavam, eu ficava muito nervosa, sumia tudo, eu ol hava para trás e quando eu via, a prova já não tava na minha frente mais (S2). 0 olhar para trás não era para "colar" de algum colega. Era para se situar na sala de aula, entender o seu contexto. Mas, o professor retirava a prova do surdo, sem o mesmo perceber. O sentimento do surdo em dias de provas acabava sendo de solidão, de abandono e de tristeza:

Faço prova normal, igual aos ouvintes. 0 mesmo vocabulário. Já cansei de pedir para o professor para fazer uma prova que tivesse vocabulário mais fácil, que desse para eu entender melhor [...] 0 professor não aceita que a minha prova deva ser diferenciada. Ele acha que a minha prova deve ser igual a todos e eu me sinto muito triste (S3).

Essealuno (S3) também rel ata que uma prova diferenciada seria muito melhor eproveitosa, porquetinha muitas dúvidas sobre o conteúdo das disciplinas. Mas, diz que o professor e os colegas não entendem o que pede e sugere, porque não dispõem de uma língua compartilhada: não enten dem o que estou pedindo, não têm uma língua própria que o surdo tem, que é diferente (S3).

Essedepoimento mostra a necessidadeda presença da língua desinais, do intérprete, no ensino superior. Não parece que a questão é com o vocabulário, com a "simplificação do vocabulário", mas com o acesso ao conteúdo trabal hado. A presença da língua de sinais em aula garantiria o acesso ao conteúdo curricular e a interlocução, negada a esse aluno.

A maior parte das atividades escolares do surdo, no ensino superior, parecem realizadas fora da instituição de ensino: a maioria dos trabal hos é realizada dentro da sala [...] então o professor acha melhor fazer dentro da sala de aula, pesquisa, discussão, tudo em grupo. Só que eu faço muita coisa fora porque não dou conta de fazer dentro da escola (S3).

Esse depoimento revela como tem sido difícil a participação do aluno surdo no contexto escolar e a interlocução na escola. Esse aluno realiza suas atividades individual mente porque os instrumentos que lhe permitem a inserção e atuação no contexto não estão presentes em sala de aula. Assim, o surdo sentese rejeitado, incapaz de interagir em grupo e com a sensação de estar errado, como no depoimento:

Tinha esta parte de rejeição da classe, eu acabei fazendo [...] sozinha. Tinha hora para entregar o trabalho em sala de aula e o grupo, cada um pensava diferente e eu também pensava diferente, então, ficava mais difícil. Eu fazendo sozinha, eu achava que eu estava certa daquela maneira, mesmo estando errada (S2). 
Esserelato mostra como o aluno surdo se vêobrigado a realizar sozinho as tarefas. O seu relacionamento com o grupo vai se tornando conflituoso. Cada pessoa pensa diferente, mas o surdo percebia que a sua maneira diferente de pensar não contava para o grupo, como a seguir.

\begin{abstract}
Eu tinha dificuldade em desenvolver em grupo, porque o grupo para mim era mais complicado, porque eu pensava sozinha e raciocinava sozinha. $M$ as como tem várias pessoas juntas, aí meu raciocínio num valia nada. Eu preferia fazer sozinha a fazer em grupo. $M$ as às vezes tinha grupo, eu para trás, eu ficava sem nota em trabalho em grupo (S2).
\end{abstract}

Entretanto, os colegas de sala, muitas vezes, substituíam o professor no processo educacional desse aluno. O surdo copiava em português o que o professor escrevia, mas quem explicava para ele era um colega:

\begin{abstract}
Era muito difícil mesmo, fazer ditado na época, era rapidez de captar a composição, não tinha rapidez nenhuma, eu era bem mais fraca, as notas eram bem mais baixas. [...] $\mathrm{N} \mathrm{a}$ faculdade, tive várias ajudas mesmo deal unos defora quevinham, conversavam comigo e, com esta ajuda, eu consegui não atrapalhar a aula do professor, toda hora ficar perguntan do, mas assim aprendi bastante. A lém de ler, ela explicava, além dela apren der também junto comigo, ela também explicava, ela compreendia melhor. Eu ficava em frente porque ficava mais fácil a leitura labial para mim (S2).
\end{abstract}

Esse depoimento mostra que apesar da falta de interlocução ainda era possível uma troca solidária entre o al uno eos col egas declasse: el es aprendiam um com o outro.

\title{
Considerações finais
}

Os dados obtidos, de um modo geral, revelam que os surdos são capazes, produtivos, solidários e interessados em prosseguir no seu processo de escolarização, apesar dos impedimentos e dificuldades em sala de aula e nas dependências das instituições de ensino superior.

A tualmente, as propostas para transformar as condições do surdo no ensino superior sereferem, primeiramente, ao direito da presença desua língua na escola, por meio do intérprete. O intérprete é aquele profissional que vai garantir ao surdo o acesso aos conteúdos curriculares.

A presença de intérprete, contudo, embora necessária não parece, ainda, suficiente. O intérpretenão domina o emprego demétodos deensino mais adequados ao surdo enão é representante da cultura surda. O apoio de professor de surdos eas ações educacionais no ensino de libras por professores surdos viabilizam estratégias de ensino mais adequadas aos alunos surdos ea presença transformadora da escola da comunidade surda e da sua cultura. O papel do educador surdo ultrapassa a questão linguística "é ele que poderá construir, junto aos seus pares, estratégias de 
identificação que possam ser vislumbradas num processo sócio-histórico mais amplo, não fragmentado" (NICOLUCCI, 2006, p. 86).

A aprendizagem deve acontecer em contato, em inter-relação, no diálogo. $\mathrm{Na}$ inter-relação é construído o significado dos conteúdos para a vida dos alunos, ou seja, o processo de aprendizagem se torna significante na interrelação e os diálogos só acontecem quando há uma língua compartilhada. Uma escola inclusiva, que pretende criar condições para um ensino de qualidade para a multiplicidade de todos os seus alunos, deve garantir o ensino na língua desses alunos.

A legislação atual do Brasil (BRASIL, 2005a eb) exige, além do ensino de libras e em libras, o ensino do português escrito como segunda língua da comunidade surda. O domínio da língua portuguesa escrita possibilita obter informações sobre a sociedade em que o aluno surdo vive, possibilitando a constituição do surdo como sujeito bilíngue e bicultural.

Em síntese, todas as dificuldades narradas pelos participantes deste estudo vão permanecer enquanto a escola for organizada e planejada apenas para os ouvintes, sem considerar a multiplicidadedeseus al unos ea especificidade de outras culturas presentes na sociedade. Se a escola não buscar o caminho bilíngue e multicultural, conforme exigem as comunidades linguísticas surdas, essas dificuldades não poderão ser superadas.

\section{REFERÊNCIAS}

BRASIL. D ecreto № 5626, de 22 de dezembro de 2005a - Regulamenta a Lei no 10.436, de 24 de abril de 2002, que dispõe sobre a Língua Brasileira de Sinais Libras, e o art. 18 da Lei no 10.098 de 19 de dezembro de 2000. Disponível em: https:/ / www.planalto.gov.br/ ccivil/_A to2004-2006/2005/ Decreto/ D5626.htm. Acesso em: 22 jan. 2006.

BRASI L. Ministério da Educação - Secretaria de Educação Especial. D esen volv ven do competên cias para 0 aten dimento às necessidades educacionais de alunos surdos. Brasília: MEC/ SEESP, 2005b.

BRASIL. Lei no 10406, de 10 de janeiro de 2002. Institui o Código Civil brasileiro. Disponível em: http:/ / trtapl3.trt12.gov.br/ cmdg/ img_legis/ 2002/ 01100610406.htm. A cesso em: 04 mar. 2006.

BRASIL. Lei no 9394, de 20 de dezembro de 1996. Estabelece as Diretrizes e Bases da Educação Nacional. Diário Oficial da União, de 23 de dezembro de 1996.

CARVALHO, R. E. Avaliação na perspectiva das diferenças. In: CONGRESSO INTERNACIONAL SOBRE AVALIAÇÃO NA EDUCAÇÃO, 2, 2004, Pinhais e CONGRESSO INTERNACIONAL SOBRE AVALIAÇÃO NA EDUCAÇÃO, 2, 2004, Curitiba: Futuro Congresso e Eventos, 2004. 
CONADE - Consel ho Nacional dos Direitos da Pessoa Portadora de Deficiência. CONADE. Disponível em: http:/ / www.mj.gov.br/ sedh/ ct/ CONADE/ index.asp. Acesso em: 12 fev. 2006.

CRUZ, J. I. G. Consolidação de uma trajetória escolar: o ol har do surdo universitário sobre o ensino superior. 2007. 178 f. Dissertação (Mestrado em Educação) Programa de Pós-graduação em Educação do Centro Universitário Moura Lacerda, Ribeirão Preto, 2007.

DIAS, T. R. S. D.; ROCHA, J. C. M.; PEDROSO, C. C. A.; CAPORALI, S. A.. Educação bilíngüe de surdos: grupos de familiares. In: REUNIÃO ANUAL DA ASSOCIAÇÃO NACIONAL DE PESQUISADORES DA EDUCAÇÃO - ANPED, 24, Rio de Janeiro, 2001. Disponível em: www.anped.org.br/ 24/ T1551475408316.doc. Acesso em: 01 mar. 2006.

Dicionário Latim Português. Porto: Porto Editora, 2000.

DORZIAT, A. Educação de surdos no ensino regular: inclusão ou segregação? Revista de Educação Especial, n. 24, p. 77-85, 2004.

FAVORITO, W. 0 difícil são as palavras: representações de/ sobre estabelecidos e 'outsiders' na escolarização de jovens e adultos surdos. 2006. 256 f. Tese (Doutorado em Linguística A plicada) - Universidade Estadual de Campinas, Campinas, 2006.

FERREIRA, M. E. C.; GUIMARÃ ES, M. E ducação Inclusiva. Rio de Janeiro: DP\&A, 2003.

FLEURI, R. M . (Org.). E du cação intercultural: mediações necessárias. Rio de Janeiro: DP\&A, 2003.

FRANCO, M. Proposta de reformulação curricular do ensino de surdos numa perspectiva multicultural e bilingue. In: CONGRESSO IBERO-AMERICANO DE EDUCAÇÃO ESPECIAL, 3, Foz do Iguaçu,1998. A nais..., Foz do Iguaçu, 1998.

GESUELI, Z. M. Língua(gem) e identidade: a surdez em questão. Educação \& Sociedade, v. 27, no 94, p. 277-292. Campinas, SP, 2006. Disponível em: http:/ / www.scielo.br/ pdf/ es/ v27n94/ a14v27n94.pdf. Acesso em: 27 jul 2006.

IPUF - Instituto de Planejamento Urbano de Florianópolis - M oções aprovadas em plenária na 2a conferência das cidades - Florianópolis 2005. Disponível em: http:/ / www.ipuf.sc.gov.br/ conf/ resultados/ mocoes.PDF. Acesso em: 29 set.2005.

KAUCHAKJE, S. Comunidade surda: as demandas identitárias no campo dos direitos, da inclusão e da participação social. In: GESUELI, Z. M. P.; SILVA , I. R.; KAUCHAKJE, S. (Org.). Cidadania, Surdez e linguagem. São Paulo:Plexus Editora, 2003. 
LIMA, M. C. M. P.; BOECHAT, H. A.; TEGA, L. M. Habilitação fonoaudiológica da surdez: uma experiência no Cepre/ FCM/ Unicamp. In: GESUELI, Z. M. P.; SILVA, I. R.; KAUCHAKJE, S. (Org.). Cidadania, Surdez e linguagem. São Paulo: Plexus Editora, 2003.

LULKIN, S. A. O discurso moderno na educação dos surdos: práticas de controle do corpo e a expressão cultural amordaçada. In: Carlos Skliar (Org.). A surdez: um ol har sobre as diferenças. Porto Alegre: Mediação, 1998.

LUNARDI, M. L.; SKLIAR, C. B. Estudos Surdos e Estudos Culturais em Educação: um debateentre professores ouvintes esurdos sobre o currículo escolar. In: LACERDA, C. B. F.; GÓES, M. C. R. (Org.). Surdez: processos educativos e subjetividade. São Paulo: Lovise, 2000. p. 11-22.

MOREIRA, A. F. B. Currículo, diferença cultural e diálogo. E ducação \& Sociedade, v. 79, p. 15-38, 2002.

MOURA, M. C. 0 surdo: caminhos para uma nova identidade. Rio de Janeiro: Revinter, 2000.

NICOLUCCI, D. Educação de surdos: uma proposta de intervenção na escola pública. 2006. 98 f. Dissertação (Mestrado em Educação) - Programa de PósGraduação em Educação do Centro Universitário Moura Lacerda. Ribeirão Preto, 2006.

PEDRoso, C. C. A. Com a palavra o surdo: aspectos do seu processo de escolarização. 2001. 115 p. Dissertação ( Mestrado em Educação Especial) Programa de Pós-graduação em Educação Especial da Universidade Federal de São Carlos. São Carlos, 2001.

PEREIRA, I. Dicionário Grego-Português e Português-Grego. Porto: Livraria do A postolado da Imprensa, 1990. p. 814.

PEREIRA, M. C. C. Bilinguismo e aquisição da linguagem por crianças surdas In: MENDES, Enicéia G.; ALMEIDA, M. A mélia.; WILLIAMS, L. C. A. (Org.). Temas em educação especial: avanços recentes. São Carlos: Editora da UFSCar, 2004, p. 43-48.

PERLIN, G. Identidades surdas. In: SKLIAR, C. (Org.). A Surdez: um olhar sobre as diferenças. Editora Mediação. Porto Alegre. 1998. p. 51-73.

QUADROS, R. M. Educação de surdos: efeitos de modalidade e práticas pedagógicas. MENDES, E. G.; ALMEIDA, M. A..; WILLIAMS, L. C. A. (Org.). Temas em educação especial: avanços recentes. São Carlos, SP: Editora da UFSCar, 2004. p. 55-60.

QUADROS, R. M. Políticas lingüísticas: as representações das línguas para os surdos e a educação de surdos no Brasil. Disponível em:< http:/ / www.ipol.org.br/ ler.php?cod=382>. A cesso em: 03 nov. 2006. 
SÁ, N. R. L. O discurso surdo: a escuta dos sinais. In: SKLIAR, C. (Org.). A surdez: um olhar sobre as diferenças. Porto Alegre : Mediação, 1998. p. 167-192. SOUZA, M. I. P.; FLEURI, R. M. Entre limites e limiares de culturas: a educação na perspectiva intercultural. In: FLEURI, R. M. (Org.). Educação Intercultural: mediações necessárias. Rio de Janeiro: DP\&A, 2003. p. 51-84.

SKLIAR, C. Educação e exclusão: abordagens sócio-antropológicas em Educação Especial. Porto Alegre: Mediação, 1997.

SKLIAR, C. A Surdez: um olhar sobre as diferenças. Porto Alegre: Editora Mediação, 1998.

SKLIAR, C. A tualidade da educação bilíngüe para surdos: processos e projetos pedagógicos. Porto Alegre: Mediação. 1999.

TARTUCI, D. A lunos surdos na escola inclusiva: ocorrências interativas e construção de conhecimentos. Disponível em: www.anped.org.br/ 25/ duceriatartucit15.rtf. A cesso em: 27 nov. 2005. 